\title{
Recent developments in HIV-related kidney disease
}

\begin{abstract}
Although kidney disease has been a recognized complication of HIV infection since the beginning of the HIV epidemic, its epidemiology, underlying causes and treatment have evolved in developed countries where HAART has been widely available. HIV-associated nephropathy and HIV immune complex-mediated kidney disease were the prominent renal diagnoses in the earlier period of the HIV epidemic. While HIV immune complex-mediated kidney disease remains a common finding among HIV-infected individuals with kidney disease, the incidence of HIV-associated nephropathy has been diminishing in developed countries. The role of the metabolic effects of long-term HAART exposure and nephrotoxicity of certain antiretroviral medications on the development and progression of chronic kidney disease is now of increasing concern. The long-term clinical implications of acute kidney injury among HIVinfected persons are increasingly recognized. Kidney disease in HIV-infected persons continues to be a major risk factor for morbidity and mortality in this patient population; therefore, early recognition and treatment of kidney disease are imperative in lessening the impact of kidney disease on the health of HIV-infected individuals. This review focuses on recent developments and ongoing challenges in the understanding, diagnosis and management of HIV-related kidney disease.
\end{abstract}

KEYWORDS: glomerular filtration rate HIV HIVAN kidney disease serum creatinine tenofovir

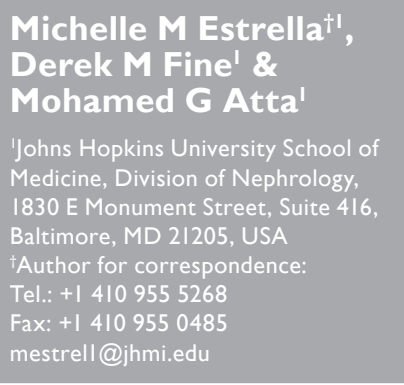

\section{MedscapeCME" Medscape: Continuing Medical Education Online}

This activity has been planned and implemented in accordance with the Essential Areas and policies of the Accreditation Council for Continuing Medical Education through the joint sponsorship of Medscape, LLC and Future Medicine Ltd. Medscape, LLC is accredited by the ACCME to provide continuing medical education for physicians. Medscape, LLC designates this educational activity for a maximum of 1.0 AMA PRA Category 1 Credits ${ }^{\mathrm{TM}}$. Physicians should only claim credit commensurate with the extent of their participation in the activity. All other clinicians completing this activity will be issued a certificate of participation. To participate in this journal CME activity: (1) review the learning objectives and author disclosures; (2) study the education content; (3) take the post-test and/or complete the evaluation at www.medscapecme. com/journal/hivtherapy; (4) view/print certificate.

\section{Learning objectives}

Upon completion of this activity, participants should be able to:

- Distinguish risk factors for kidney disease among patients with HIV infection

- Examine effective diagnostic strategies for assessment of kidney disease in patients with HIV infection

- Construct appropriate management strategies for HIV-associated nephropathy that recognize the impact of antiretroviral medications on kidney function 
Financial \& competing interests disclosure

Editor: Elisa Manzotti, Editorial Director, Future Science Group. Disclosure: Elisa Manzotti has disclosed no relevant financial relationships.

Authors and Credentials: Michelle M Estrella, Johns Hopkins University School of Medicine, Division of Nephrology, 1830 E. Monument Street, Suite 416, Baltimore, MD 21205, USA. Disclosure: Michelle M Estrella is supported by the NIH-NIDDK grant 1K23DK081317.

Derek M Fine, Johns Hopkins University School of Medicine, Division of Nephrology, 1830 E. Monument Street, Suite 416, Baltimore, MD 21205, USA. Disclosure: Derek M Fine has received speakers honoraria from ViiV Pharmaceuticals. Mohamed G Atta, Johns Hopkins University School of Medicine, Division of Nephrology, 1830 E. Monument Street, Suite 416, Baltimore, MD 21205, USA. Disclosure: Mohamed G Atta has disclosed no relevant financial relationships. CME Author: Charles P Vega, Department of Family Medicine, University of California, Irvine, CA, USA. Disclosure: Charles P Vega has disclosed no relevant financial relationships.

HIV-infected individuals are at an increased risk for acute kidney injury (AKI) and chronic kidney disease (CKD). Both AKI and CKD, including microalbuminuria, are associated with increased risk for cardiovascular disease and mortality among HIV-infected individuals versus the general HIV-uninfected population. While the mechanisms by which kidney disease impacts outcomes in HIV-infected persons remain largely unclear, timely detection and accurate diagnosis of kidney disease in HIVinfected individuals are necessary in averting further renal injury and instituting appropriate treatment. This paper reviews recent advances regarding the epidemiology, pathogenesis and management of kidney disease in HIV infection.

\section{Renal disorders \& their adverse effects in HIV infection}

- Acute kidney injury

HIV-infected individuals appear to have higher risk for AKI compared with HIV-uninfected persons. Among ambulatory HIV-infected persons, AKI incidence was estimated to be 5.9 per 100 person-years [1]. Among hospitalized patients, approximately $18 \%$ of HIVinfected patients developed AKI [2], with nearly a threefold higher risk of AKI compared with HIV-uninfected patients [3].

For HIV-infected persons who present with AKI, the differential diagnosis may be broad. Among ambulatory patients who develop AKI, the majority are thought to have pre-renal azotemia $(38 \%)$, acute tubular necrosis $(20 \%)$ or drug-related AKI (15\%), and not necessarily AKI directly related to their HIV infection [1]. Patients who develop AKI during their hospitalization often have acute tubular necrosis, acute interstitial nephritis, urinary obstruction or drug-related nephrotoxicity. In a case series of HIV-infected individuals who underwent kidney biopsies and were diagnosed with acute interstitial nephritis, most cases were due to nonsteroidal anti-inflammatory drugs or sulfamethoxazole/trimethoprim. Antiretroviral medications were implicated in only three patients [4].

\section{Chronic kidney disease}

While $10-30 \%$ of HIV-infected individuals have microalbuminuria or proteinuria [5], the prevalence of impaired kidney function (defined as an estimated glomerular filtration rate [eGFR] $<60 \mathrm{ml} / \mathrm{min} / 1.73 \mathrm{~m}^{2}$ ) varies from 2.4 to $10 \%$ depending upon the social and demographic characteristics of the examined population [6,7] . HIV-associated nephropathy (HIVAN), a specific histopathologic form of focal segmental glomerulosclerosis (FSGS), has traditionally been regarded as the predominant renal lesion among HIVinfected persons of African descent [8]. Recent studies using HIVAN mouse models suggest that two pathways may be involved in HIVAN pathogenesis. Compared with control mice, renal epithelial and tubular cells from HIVAN mice demonstrated increased expression of mesenchymal markers, such as $\alpha$-smooth muscle actin $(\alpha-S M A)$ and fibroblast-specific protein-1 (FSP1), suggesting that epithelial mesenchymal transition may contribute to HIVAN [9]. In addition, the mammalian target of rapamycin (mTOR) pathway may also contribute to HIVAN. Using the HIVAN mouse model, the investigators demonstrated the activation of the mTOR pathway in the renal cortices. Treatment with the mTOR inhibitor rapamycin led to milder HIVAN histopathology [10].

Various other renal lesions may also occur in HIV-infected persons. Among HIVinfected individuals of non-African descent, HIV-related immune complex-mediated kidney disease (HIVICK) develops as a direct result of deposition or in situ development of HIV antigen-specific immune complexes [11]. 
Other cases mimic immune-complex diseases observed in HIV-uninfected individuals and include IgA nephropathy, lupus-like glomerulnephritis,post-infectious glomerulonephritis and hepatitis C-related membranoproliferative glomerulonephritis. In addition, interstitial nephritis, thrombotic microangiopathy and more traditional CKD causes, such as diabetic or hypertensive nephropathy, may occur in HIV infection [12].

\section{- Adverse effects of AKI \& CKD}

In the early part of the HIV epidemic, AKI and CKD were associated with earlier progression to AIDS and death [13]. In the modern HAART era, AKI and CKD remain strongly associated with death, but are also increasingly recognized as important risk factors for cardiovascular events. In a large population of hospitalized HIV-infected persons, the incidence of cardiovascular disease and heart failure increased incrementally with AKI severity $[2,14]$. Among HIV-infected individuals requiring dialysis for AKI, the risk for cardiovascular disease and heart failure were 1.96- and 4.20-fold greater compared with individuals who did not develop AKI during their hospitalization [2]. A similar association was also observed among HIVinfected individuals with CKD. Increasing microalbuminuria was associated with escalating risk for incident cardiovascular disease and heart failure, independent of eGFR level [15]. In a case-control study of 315 predominantly black HIV-infected individuals, the odds of a cardiovascular event was twofold greater among individuals with proteinuria and 1.2-fold greater per $10 \mathrm{ml} / \mathrm{min} / 1.73 \mathrm{~m}^{2}$ lower eGFR. These risks were independent of diabetes, hypertension, dyslipidemia, previous cardiovascular events, CD $4^{+}$cell count and HIV-1 RNA level [16]. The mechanism by which kidney disease and cardiovascular disease are associated is not fully elucidated. However, the association likely involves shared traditional risk factors, such as diabetes and hypertension, but also nontraditional risk factors commonly observed in HIV-infected persons, such as inflammation.

\section{Association between AKI \& CKD}

In HIV infection, the risk of developing endstage kidney disease (ESKD) increases incrementally with AKI severity. Among hospitalized HIV-infected patients, those who experienced a serum creatinine increase of at least $0.3 \mathrm{mg} / \mathrm{dl}$ or $150 \%$ were 1.37 -times more likely to progress to ESKD compared with those who did not develop AKI. This increased to 20.36-fold higher risk among HIV-infected individuals requiring dialysis [2]. Unfortunately, individuals with CKD are at a significantly higher risk of developing AKI during their hospitalization. This risk for in-hospital AKI rises dramatically with the severity of CKD at the time of admission (odds ratio: 1.95-40.07) [17]; this converse association between CKD and AKI has not been examined in the context of HIV infection.

\section{Risk factors for kidney disease in HIV infection \\ - Genetic susceptibility to \\ HIV-related CKD}

Similar to the general HIV-uninfected population, racial disparities in the rapidity of progression to ESKD exist between HIV-infected African-Americans and Caucasians [18]. HIVinfected individuals of African descent, especially those who have a family history of ESKD, have long been recognized as having greater risk for HIV-related kidney disease [19]. These observations implicate the role of genetic susceptibility in HIV-related kidney disease. This hypothesis has been supported by recent advancements in genome-wide association studies in transgenic mouse models of HIVAN and in humans with nondiabetic ESKD.

The transgenic mouse model of HIVAN has key, strain-specific differences in disease susceptibility depending on the genetic make-up of the mouse. In this model, a strain of HIV-1 devoid of replicative capability is randomly incorporated as a transgene into the murine genome [20]. HIV-1 transgenic mice with an FVB/NJ background develop kidney disease with several features of HIVAN. However, the renal phenotype is modified, ranging from no appreciable renal abnormalities to severe kidney disease, when this strain is crossed to a number of other inbred mouse strains, suggesting that the host genetic background is important in determining kidney disease development [21-23]. Genome-wide linkage analyses of these HIVAN mice have been used to identify loci within the mouse genome that are associated with HIVAN susceptibility [24]. The first locus, HIVAN1, is located on mouse chromosome 3 and corresponds with the locus 3q25-27 in humans, which has been linked with diabetic and hypertensive kidney disease [25,26]. Since the identification of HIVAN1 [21], two additional susceptibility loci have been discovered: HIVAN2 and HIVAN3 
on mouse chromosomes 13 and 4, respectively. The latter two loci account for $7-10 \%$ of the variance in disease severity in the HIVAN mouse model [23]. Expression quantitative trait locus (eQTL) mapping has afforded the study of the effects of HIVAN1 and HIVAN2 on the expression of certain genes important in podocyte function. In this method, gene expression levels are the outcomes of interest and handled as quantitative traits, and regulatory networks underlying HIVAN may be elucidated. Utilizing eQTL analysis, Papeta and colleagues have demonstrated that HIVAN1 and HIVAN2 modulate the expression of a network of podocyte genes (including NPHS1, NPHS2, SYNPO, KIRREL and $M Y H 9$ ) located distantly from these susceptibility loci [23]. Additional experiments showed that the presence of HIVAN1 or HIVAN2 led to altered expression levels of these podocyte genes without leading to renal disease. However, HIV infection of mice carrying either HIVAN1 or HIVAN2 manifested more severe disturbances in expression levels of these podocyte genes and development of renal disease [23]. Such a regulatory network is likely to be significant in the pathogenesis of HIVAN.

The importance of the host genetic background in the development of HIVAN has also been highlighted in human studies. Using mapping by admixture linkage disequilibrium (MALD), which was based on the observed racial differences in ESKD prevalence between AfricanAmericans and Caucasians, two independent studies showed a strong association between the region of chromosome $22 \mathrm{q} 12$ and nondiabetic ESKD (including HIVAN) [27,28]. This region contains 21 previously recognized genes. The initial investigations focused on variants of the MYH9 gene because of its renal expression (especially in podocytes), association with Mendelian forms of kidney disease and protein product (nonmuscle myosin heavy-chain isoform IIA). Its protein product co-localizes with actin, an important component of the podocyte cytoskeletal system, suggesting a vital role of this protein in the contractile mechanisms of podocytes and podocyte foot processes [29]. In total, 14 MYH9 single nucleotide polymorphisms (SNPs) were associated with greater odds of ESKD. Haplotype E-1 containing the four SNPs rs4821480, rs2032487, rs4821481 and rs3752462 was associated with a sixfold increased risk for biopsy-proven HIVAN [27]. A similar association was observed in the Family Investigation of Nephropathy and Diabetes (FIND) Study between HIV-related
ESKD, but was weaker [28]. The association between these MYH9 SNPs and kidney disease has been replicated in follow-up studies and extended to Hispanic-Americans [30-33].

Although $\mathrm{MYH} 9$ is an attractive candidate gene, emerging data suggest that variants of the APOL1 gene, which are in strong linkage disequilibrium with $M Y H 9$, may actually harbor the causal variant or contribute to the renal disease attributed to $M Y H 9$. In an association study among African-Americans with and without FSGS, two APOL1 SNPs were strongly associated with FSGS. Individuals with two risk alleles had over tenfold greater odds of FSGS compared with persons with none or only one risk allele. Adjustment for these newly discovered APOL1 risk variants accounted for the excess risk of kidney disease previously attributed to the $M Y H 9$ risk variants [34]. A separate study among African-Americans and Hispanic-Americans with nondiabetic ESKD observed similar findings [35]. APOL1 risk variants confer resistance to the parasite Trypanosoma, and therefore protection against the African sleeping sickness. These APOL1 risk variants likely arose through positive natural selection [34]; however, the mechanism by which they may lead to kidney disease is unclear. APOL1 encodes for apolipoprotein A-1 and may be involved in apoptosis, autophagy and vascular injury. However, renal expression of APOL1 mRNA has only been demonstrated in cultured human podocytes [36]. Research to clarify the association between genes within chromosome $22 \mathrm{q} 12$ and kidney disease is actively ongoing. Since not all individuals who are homozygous for the $M Y H 9$ or APOL1 risk alleles develop kidney disease, additional renal injuries of genetic and/or environmental nature are necessary to manifest renal disease. One such injury may be HIV infection.

\section{- Other risk factors for kidney disease in HIV infection}

Chronic kidney disease in HIV-infected individuals develops as a result of both viral-related risk factors and more traditional risk factors for kidney disease. HIVAN develops among HIVinfected persons with high viremia that typically occurs in the context of advanced HIV disease stage or during acute HIV infection [37,38]. HIV-1 infection of renal parenchymal cells is thought to be important in the development of HIVAN [39]; however, the mechanism by which HIV-1 enters these cells does not appear to involve the chemokine receptors that the virus uses to infect 
$\mathrm{CD}^{+}{ }^{+}$lymphocyte cells [40]. Nonetheless, protein products of the viral genes (e.g., nef and $v p r$ ) are sufficient to induce HIVAN in susceptible transgenic murine models [41,42].

In addition to HIV-1, the hepatitis $\mathrm{C}$ virus is also an important contributor to kidney disease in the HIV-infected population. Approximately a third of HIV-infected individuals are coinfected with hepatitis C; however, this estimate is significantly higher among HIV-infected hemophiliacs and injection drug users [43]. In a meta-analysis of 27 studies, the risks for proteinuria and AKI were higher among individuals dually infected with HIV and hepatitis C compared with individuals infected with HIV alone, with relative risks of 1.15 and 1.64 , respectively [44]. More recently, hepatitis C antibody positivity was associated with nearly a twofold increased risk of developing CKD among HIVinfected individuals [45]. However, a large proportion of dually infected persons also use illicit drugs, which may adversely affect kidney function [46]. Cocaine, in particular, has been linked to arterionephrosclerosis, a histopathological finding linked to hypertensive kidney disease, among HIV-infected cocaine users despite the absence of hypertension [47]; therefore, a portion of the increased risk for kidney disease may be attributable to renal effects of illicit drugs rather than the hepatitis $\mathrm{C}$ virus.

In addition to these viral-related factors, more traditional risk factors are likely to explain an increasing proportion of kidney disease in HIV infection due to the general aging of HIVinfected persons and earlier use and increased availability of HAART. In the USA, diabetes and hypertension account for more than half of the cases of ESKD in the HIV-uninfected population. The relative contributions of these diseases to kidney disease are anticipated to increase in other developed countries [48]. Elevated lowdensity lipoprotein (LDL) and decreased highdensity lipoprotein (HDL) levels have also been independently associated with kidney function decline [49]. Among HIV-infected persons, diabetes, hypertension and dyslipidemia have been associated with HAART exposure. HIVinfected individuals receiving HAART experience a fourfold higher incidence of diabetes compared with HIV-uninfected persons [50]. Similarly, systolic hypertension develops after HAART exposure of 2 years or longer [51]. In a recent study comparing HIV-uninfected individuals matched on age, gender, race, smoking status and body mass index with HIV-infected persons aged 50 years or older, HIV-infected individuals had a higher prevalence of hypertension (38 vs 54\%, respectively) [52]. HIV infection also leads to reductions in LDL and HDL levels; HAART, however, is associated with increased LDL, but depressed HDL levels [53]. These HAART-related metabolic abnormalities likely play a role in the development of CKD among HIV-infected individuals as they do in the general population. Insulin resistance and hypertension correlate with more severe albuminuria [5]. These observations were supported by recent findings from the EuroSIDA Study in which hypertension and diabetes were independent predictors of incident CKD [45]. Moreover, diabetes and hyperlipidemia were associated with greater decline in kidney function among HAART-treated, HIV-infected individuals [54].

\section{Diagnosis \& management of kidney disease in HIV infection \\ - Recognition of kidney disease}

Early recognition of kidney disease in HIVinfected persons is imperative in preventing further renal damage and instituting appropriate management efficiently. The diagnosis of AKI is based on serum creatinine rather than eGFR, which assumes that creatinine clearance is constant, an invalid assumption in AKI [55]. The AKI Network (AKIN) has developed diagnostic criteria to facilitate research on AKI and to improve AKI recognition and management (Box I) [56]. These criteria include urine output because it is an early indicator of AKI and renal recovery and often precedes changes in serum creatinine.

\section{Box 1. Definition and staging of acute kidney injury.}

\section{Acute kidney injury}

Development of any one of the following within $48 \mathrm{~h}$ :

- Absolute increase in $\mathrm{SCr} \geq 0.3 \mathrm{mg} / \mathrm{dl}$

- Percentage increase in $\mathrm{SC} r \geq 50 \%$ from baseline

- Decrease in urine output to $<0.5 \mathrm{ml} / \mathrm{kg} / \mathrm{h}$ for $>6 \mathrm{~h}$

\section{Staging of acute kidney injury}

\section{Stage 1}

- Increase in $\mathrm{SCr} \geq 0.3 \mathrm{mg} / \mathrm{dl}$ or $\geq 150-200 \%$ from baseline

- Urine output $<0.5 \mathrm{ml} / \mathrm{kg} / \mathrm{h}$ for $>6 \mathrm{~h}$

\section{Stage 2}

- Increase in SCr $>200-300 \%$ from baseline

- Urine output $<0.5 \mathrm{ml} / \mathrm{kg} / \mathrm{h}$ for $>12 \mathrm{~h}$

\section{Stage 3}

- Increase in $\mathrm{SCr}>300 \%$ from baseline

- $\mathrm{SCr} \geq 4 \mathrm{mg} / \mathrm{dl}$ with acute $\mathrm{SCr}$ increase $\geq 0.5 \mathrm{mg} / \mathrm{dl}$

- Urine output $<0.3 \mathrm{ml} / \mathrm{kg} / \mathrm{h}$ for $>24 \mathrm{~h}$ or no urine output for $\geq 12 \mathrm{~h}$

SCr: Serum creatinine.

[56]. 
To assist clinicians in the recognition of CKD, the Infectious Diseases Society of America (IDSA) guidelines recommend urinalysis and estimation of kidney function for all HIVinfected persons at the time of HIV diagnosis [57]. While urine dipsticks are more readily available and simple to use, they may not detect lower levels of clinically significant albuminuria. Comparison of urine dipsticks and random urine protein-to-creatinine ratios in HIVinfected individuals has demonstrated that the former may miss up to $21 \%$ of individuals with low-to-moderate proteinuria (300-999 mg/g creatinine) [58]. Therefore, proteinuria screening should rely on random urine albumin-to-creatinine ratios [59]. In persons with higher levels of albuminuria or with known proteinuria, random urine protein-to-creatinine ratios serve as accurate surrogates for 24-h urine protein quantifications, but may be inaccurate in the context of AKI, in individuals with extremely high or low muscle mass, and in persons with very advanced CKD [55,60,61].

Several GFR-estimating equations based on serum creatinine exist. The two most commonly used equations in clinical practice are the Cockcroft-Gault equation and the Modification of Diet in Renal Disease (MDRD) equation (Table I) [62,63]. The abbreviated MDRD equation contains only four of the variables from the original equation [64], while the re-expressed MDRD equation is used with standardized serum creatinine measurements [65]. The CKD Epidemiology Collaboration (CKD-EPI) equation, which was developed in a larger population, is thought to provide more precise and accurate estimates of GFR compared with the MDRD equation [66]. However, all of these equations have diminished accuracy at eGFR levels above $60 \mathrm{ml} / \mathrm{min} / 1.73 \mathrm{~m}^{2}$ [66-68]. None has been thoroughly validated in HIV-infected individuals.
The early studies evaluating the accuracy of the Cockcroft-Gault equation in HIV-infected persons yielded conflicting results, perhaps due to their reliance on small sample sizes and 24-h urine collections for creatinine clearance as the gold standard [69-71]. A comparison of the Cockcroft-Gault and MDRD equations to GFR measurements using a radiotracer in $27 \mathrm{HIV}$ infected individuals demonstrated that the GFR estimates yielded by the MDRD equation were generally more accurate than those based on the Cockcroft-Gault equation. While $89 \%$ of the MDRD-based eGFRs were within 30\% of measured GFR, only $70 \%$ of the GFR estimates based on the Cockcroft-Gault equation were within $30 \%$ of the measured GFR. As observed in the general population, the accuracy of both estimating equations was lower at higher levels of kidney function [72]. Additional validation studies that include larger study populations of HIV-infected individuals and also evaluate the performance of the CKD-EPI equation are forthcoming.

Serum cystatin $\mathrm{C}$ has been evaluated as an alternative or additional renal biomarker in estimating kidney function. In elder HIVuninfected individuals, cystatin $\mathrm{C}$ predicts subsequent cardiovascular disease and mortality better than serum creatinine [73]. Like serum creatinine, however, cystatin $\mathrm{C}$ is influenced by age, gender and race [74,75]. Estimates of GFR using the equation with cystatin $\mathrm{C}$ alone and with adjustments for age, gender and race were slightly less accurate compared with those based on the equation with both cystatin $\mathrm{C}$ and serum creatinine, with 83 versus $89 \%$ of the eGFRs within $30 \%$ of the measured GFR, respectively [75]. The comparison of cystatin-based GFR estimates with measured GFR in HIVinfected persons showed that cystatin C-based eGFR generally underestimated the measured

\section{Table 1. Glomerular filtration rate-estimating equations.}

Equation

Cockcroft-Gault

Abbreviated MDRD

Re-expressed MDRD

CKD-EPI

\section{Expression}

$\mathrm{CrCl}=([140-$ age $)] \times$ weight $/(72 \times \mathrm{SCr}) \times 0.85$ if female

$\mathrm{eGFR}=186 \times \mathrm{SCr}^{-1.154} \times$ age $^{-0.203} \times 0.742$ if female $\times 1.212$ if black

$\mathrm{eGFR}=175 \times$ standardized SCr.154 $\times$ age $\mathrm{S}^{-0.203} \times 0.742$ if female $\times 1.212$ if black

$\mathrm{eGFR}=141 \times \min (\mathrm{SCr} / \kappa, 1)^{\alpha} \times \max (\mathrm{SCr} / \kappa, 1)-1.209 \times 0.933^{\text {age }} \times 1.018$ if female $\times 1.159$ if black

where $\kappa$ is 0.7 for males and 0.9 for females; $\alpha$ is -0.411 for males and -0.329 for females; min indicates minimum of $\mathrm{SCr} / \kappa$ or 1 ; and max indicates maximum of $\mathrm{SCr} / \kappa$ or 1

CysC only

$\mathrm{SCr}$ and $\mathrm{CysC}$
$\mathrm{eGFR}=127.7 \times \mathrm{CysC}^{-1.17} \times$ age $^{-0.13} \times 0.91$ if female $\times 1.06$ if black

$\mathrm{eGFR}=177.6 \times \mathrm{SCr}^{-0.65} \times$ Cys $\mathrm{C}^{-0.57} \times$ age $^{-0.20} \times 0.82$ if female $\times 1.11$ if black
Ref.

Age is given in years, weight in $\mathrm{kg}, \mathrm{SCr}$ in $\mathrm{mg} / \mathrm{dl}$ and CysC in $\mathrm{mg} / \mathrm{l}$.

CKD-EPI: Chronic Kidney Disease Epidemiology Collaboration; CrCl: Estimated creatinine clearance; CysC: Serum cystatin C; eGFR: Estimated glomerular filtration rate; MDRD: Modification of Diet in Renal Disease; SCr: Serum creatinine. 
GFR and had poor accuracy, with only $41 \%$ of the eGFR estimates within $30 \%$ of the measured GFR [72]. However, this study was quite small and did not use a cystatin C-based equation adjusting for age, gender and race. The poor performance of cystatin C-based eGFR in this study may also be due to the influence of additional extra-renal factors more commonly found in HIV-infected persons [76]. Studies of cystatin $\mathrm{C}$ levels in HIV-infected individuals have consistently shown higher levels in HIV-infected compared with HIV-uninfected persons [7,77,78]. Cystatin C correlated with markers of inflammation and degree of HIV viral suppression [78,79]. Although the current IDSA guidelines recommend using the MDRD equation to estimate kidney function in HIV-infected individuals, based on the authors' observations in clinical practice and unpublished data, the CKD-EPI equation likely provides a more precise and less biased estimate of kidney function in this patient population. The updated IDSA guidelines on management of kidney disease in HIV infection are currently underway.

\section{- Other potential indicators of} kidney injury

Among HIV-infected individuals, retinolbinding protein (RBP), N-acetyl- $\beta$-Dglucosaminidase (NAG), and neutrophil gelatin-associated lipocalin (NGAL) have been studied as indicators of kidney injury. RBP and NAG may reflect renal proximal tubular function [80-82], while NGAL may indicate glomerular or proximal or tubular dysfunction [83]. In a cross-sectional study of $99 \mathrm{HIV}$-infected persons with serum creatinine levels below $1.7 \mathrm{mg} / \mathrm{dl}$ and without evidence of proteinuria by urine dipstick, those receiving tenofovir had higher levels of urinary RBP excretion; however, the investigators did not observe differences in urinary NAG excretion between tenofovir and nontenofovirtreated individuals [84]. The data on the utility of NGAL in HIV-related kidney disease are also limited. HIV-infected individuals appear to have lower levels of serum NGAL compared with $\mathrm{HIV}$-uninfected persons. Among HIV-infected individuals who experienced viral suppression with HAART, the serum NGAL levels rose to near normal levels [85]. These observations suggest that serum NGAL levels may be associated with HIV-infection due to changes in neutrophil numbers and function [85]; kidney function, however, was not examined in this study. In an $\mathrm{HIV}$-infected pediatric patient, urinary NGAL levels decreased progressively upon HAART initiation for biopsy-proven HIVAN, although it remains unclear whether these changes signified improved renal tubular function or rather improved immune function [86]. In a study comparing urinary NGAL levels among HIVinfected individuals with HIVAN, HIV-infected individuals with other forms of kidney disease, and HIV-infected individuals without evidence of kidney disease, those with HIVAN had higher levels of urinary NGAL. In transgenic mouse models of HIVAN, NGAL mRNA was highly expressed in renal tubular microcysts, typically found in the human form of HIVAN [87]. Further validation of the utility of these novel biomarkers is needed before their application in clinical practice. The discovery and study of biomarkers for kidney disease are accelerating and may provide early detection of kidney disease, prediction of underlying renal histopathology and improved prognostication for kidneyrelated outcomes in HIV-infected individuals in whom early diagnosis is of the essence and kidney biopsies are not often performed outside of tertiary centers.

\section{- Management of HIV-infected patients with kidney disease}

A careful review of a patient's history and recent exposures are imperative in informing appropriate further work-up and management of kidney disease in HIV-infected individuals. Additional work-up may include assessment of the kidney function trend, examination of the urinary sediment, renal sonogram and kidney biopsy. A study of kidney biopsy from a single center showed similar incidence of complications between HIV-infected and -uninfected individuals, suggesting that ultrasound-guided percutaneous kidney biopsies in the hands of experienced operators is well-tolerated [88]. However, patients who were dually infected with HIV and hepatitis C had greater risk of biopsyrelated complications compared with individuals infected with HIV or hepatitis C alone; therefore, HIV-infected patients co-infected with hepatitis $\mathrm{C}$ should be counseled on their increased risk of biopsy-related complications.

Since adverse effects associated with kidney disease in HIV-infected persons may be due to inappropriate dosing of medications [89], drug dosages should be adjusted according to kidney function. Treatment of HIV-infected individuals with kidney disease should also encompass management of blood pressure, serum glucose 
and lipid levels. HAART initiation in persons diagnosed with HIVAN regardless of the $\mathrm{CD}^{+}$cell counts and HIV viral loads is now advocated [90-92]. Steroids and angiotensinconverting enzyme (ACE) inhibitors may also be partially effective in treating HIVAN [91,93]. The efficacy of HAART and other specific interventions (e.g., ACE inhibitors) for HIV-infected individuals with non-HIVAN kidney disease have not been studied.

\section{Impact of antiretroviral medications on kidney function}

The impact of HAART on long-term kidney function encompasses both their beneficial effect on HIV disease progression and HIVAN, but also the potential adverse effects associated with prolonged HAART exposure. In addition to the potential impact of metabolic changes related to HAART upon kidney function, certain antiretroviral medications may also affect kidney function acutely or longitudinally.

\section{- Tenofovir-associated acute nephrotoxicity}

Tenofovir, a nucleoside transcriptase inhibitor, is now a first-line agent for treatment of HAART-naive HIV-infected persons; however, it has acute and chronic renal effects that should be noted. Tenofovir enters the proximal renal tubules via the organic anion transporter protein-1 (OAT1) and to a lesser extent the OAT3 protein located along the basal membrane of

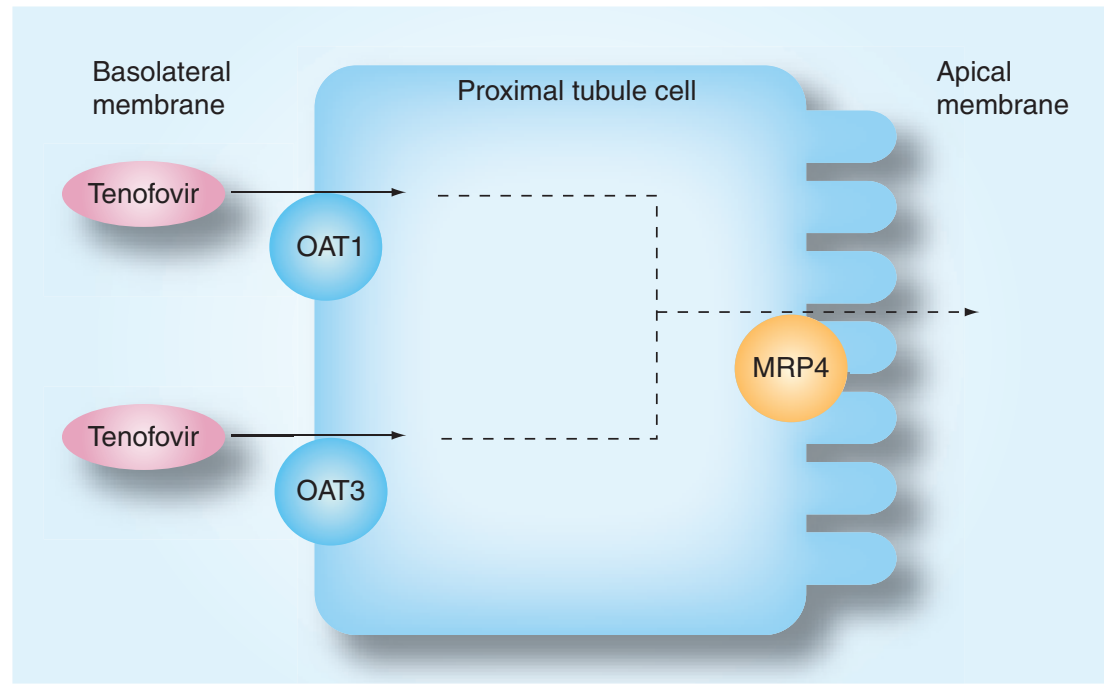

Figure 1. Excretion of tenofovir by the proximal tubule cell. Tenofovir is filtered by the glomerulus. At the basolateral membrane of the proximal tubule, tenofovir enters the cell via OAT1 and OAT3. It is then excreted into the urine via the apical MRP4.

MRP: Multidrug-resistant protein; OAT: Organic anion transporter. the proximal renal tubule cells (Figure I) [94]. Tenofovir is then excreted into the urinary tract via the multi-drug-resistant protein- 4 (MRP4) [95]. Despite a good understanding of tenofovir's renal excretion, the mechanisms by which it injures the kidneys remain unclear. Tenofovir may perturb mitochondrial function or interfere with the function of renal tubular proteins involved in its elimination [96]. Tenofovir is linked with partial or full Fanconi's syndrome, which is characterized by proteinuria, normoglycemic glycosuria, hypokalemic renal tubular acidosis and phosphaturia [97-99]. Individuals with tenofovir-induced phosphaturia may not present with accompanying hypophosphatemia, and without intervention, phosphaturia may lead to severe mineral bone disease and pathologic fractures [100,101]. Affected individuals with tenofovir-related Fanconi's syndrome may or may not have accompanying renal function impairment. Tenofovir renal toxicity may also present with acute tubular necrosis and more rarely nephrogenic diabetes insipidus $[102,103]$.

\section{- Tenofovir-associated CKD}

Although its propensity to cause Fanconi's syndrome and AKI is well-recognized, tenofovir's effect on longitudinal kidney function is debated. Clinical trials generally show that tenofovir-related Fanconi's syndrome is uncommon and that tenofovir has no or minimal effect on longitudinal eGFR [104-106]. In trials of HAART-naive persons in which tenofovir-containing HAART regimens were compared with regimens without tenofovir, the median eGFR declined similarly between both groups [105,106]. Results from observational studies are conflicting. While data from the Chelsea and Westminster HIV cohort did not show an association between tenofovir and kidney dysfunction [107], tenofovir-treated individuals in the Johns Hopkins Clinical Cohort experienced a greater decline in creatinine clearance over a period of 3 years compared with persons not receiving tenofovir (-13.3 vs $7.5 \mathrm{ml} / \mathrm{min}$ ) [108]. However, a more recent study from the same clinical cohort demonstrated only minor differences in kidney function changes over time between HIV-infected patients initiating HAART with versus without tenofovir [109]. The disparate results between the two studies reported by Gallant and Moore may be due to the latter study having only HAART-naive patients versus the earlier study, which examined both HAART-naive and -experienced 
patients. The contrary findings regarding tenofovir's effect on long-term kidney function among studies are also likely a consequence of differing study populations, differing methods of estimating kidney function, and differing CKD definitions. Participants in clinical trials with tenofovir were generally Caucasian and HAART-naive; they were also unlikely to receive concurrent nephrotoxic drugs [104-106]. Participants within observational studies were predominantly of African descent and included both HAART-naive and -experienced individuals. Moreover, participants within observational studies had additional risk factors for CKD, such as hypertension and diabetes [45,108]. Additional risk factors for tenofovir-related nephrotoxicity include older age, lower body mass, established $\mathrm{CKD}$ and certain polymorphisms of the $A B C C 2$ gene, which encodes for the MRP2 [110,111].

\section{- Other antiretroviral drugs associated} with kidney disease

Indinavir and atazanavir have also been implicated in causing longitudinal renal function decline. Indinavir has been associated with AKI due to crystal nephropathy as well as interstitial nephritis $[112,113]$. These adverse renal effects were thought to be limited to the previously prescribed doses of indinavir $(800 \mathrm{mg}$ twice per day). However, in a contemporary cohort, cumulative exposure to indinavir was associated with an 11\% rise in CKD incidence per year of exposure [45].

Atazanavir has been rarely associated with nephrolithiasis and interstitial nephritis [114,115]. In a more recent study, atazanavir was also associated with a $22 \%$ increase in incident CKD per year of exposure. When atazanavir was used in combination with tenofovir, the CKD incidence was even higher at $41 \%$ per year of exposure [45].

\section{Conclusion}

Although kidney disease has been a recognized complication of HIV infection since the onset of the HIV epidemic, its epidemiology and management has evolved with the increased availability of HAART. Both AKI and CKD impact health outcomes in the HIV-infected population, with important implications for cardiovascular disease. Several factors, including host genetic susceptibility to kidney disease, contribute to the development and progression of kidney disease in HIV-infected individuals. Estimates of kidney function have not been wellvalidated in the context of HIV infection and may be insensitive to early decrements in kidney function. Examination of the urinary protein excretion may yield earlier recognition of kidney injury in HIV infection. HAART is thought to be effective in the treatment of HIVAN; however, its efficacy in others types of kidney disease observed in HIV infection is uncertain.

\section{Future perspective}

There have been significant strides over the last two decades into the understanding of the pathogenesis of HIVAN and recognition of the risk factors for AKI and CKD in HIV-infected individuals; however, there are ongoing research questions and practical challenges that lie ahead. The means by which AKI exerts its effect on health outcomes among HIV-infected persons remain largely unknown. Possible reasons for the increased risk of death and cardiovascular events in this particular population include, but are not limited to, inappropriate drug dosing, HAART interruption and drug interactions. The pursuance of the study of these potential mechanisms is important because they are modifiable in practice.

The discovery of a locus associated with HIVAN has afforded a new direction of research in this field. Although $\mathrm{MYH} 9$ is an excellent candidate gene, research efforts thus far have failed to determine the causal variant, and the strong association of APOL1 with nondiabetic kidney further complicates these associations. The study of gene-environment and gene-gene interactions in the context of HIV infection is fascinating, but challenging due to the complex nature of renal disease phenotypes among HIVinfected persons, and issues of study design and statistical analyses of such interactions.

While HAART has been shown to be effective in the treatment of HIVAN, a similar treatment has not been developed for non-HIVAN kidney disease among HIV-infected persons. While renal biomarkers that may indicate early kidney injury are actively being pursued and may eventually prove helpful in monitoring patients receiving potentially nephrotoxic medications, evaluation of the efficacy of established renal-protective drugs (e.g., ACE inhibitors) on non-HIVAN kidney disease is still lacking. Novel medications that may reverse renal fibrosis regardless of the inciting event may soon be developed. Forthcoming studies that aim to validate GFR-estimating equations in HIV-infected individuals will facilitate these research endeavors. 


\section{Executive summary}

\section{Renal disorders \& their adverse effects in HIV infection}

- HIV-infected individuals are at greater risk for acute kidney injury (AKI) and chronic kidney disease (CKD).

- Both AKI and CKD are independently associated with cardiovascular disease and mortality.

\section{Risk factors for kidney disease in HIV infection}

- Variants of the MYH9 gene, which encodes for the non-muscle myosin heavy chain isoform IIA, have been associated with HIVassociated nephropathy (HIVAN). However, emerging data suggest that variants of the APOL1 gene, which are in strong linkage disequilibrium with $\mathrm{MYH9}$, may account for part if not all the risk of kidney disease previously attributed to $\mathrm{MYH9}$.

- Three loci within the mouse chromosome (HIVAN1, HIVAN2 and HIVAN3) have been associated with increased susceptibility to HIVAN in the transgenic mouse model of HIVAN. HIVAN1 and HIVAN2 appear to regulate the expression of a network of podocyte genes located distantly from these susceptibility loci; such a mechanism likely plays a role in the development of HIVAN in humans.

- Risk factors for CKD among HIV-infected individuals include African ancestry, HIV disease stage, hepatitis C co-infection, cocaine use, hypertension, diabetes, dyslipidemia and perhaps AKI.

\section{Diagnosis \& management of kidney disease in HIV infection}

- AKI diagnosis relies upon serum creatinine levels and urine output, while CKD diagnosis relies upon the urinary sediment and estimated glomerular filtration rate (GFR).

- Sufficient validation of currently available GFR-estimating equations in the HIV-infected patient population is lacking. The preferred GFR-estimating equation for HIV-infected individuals is the CKD Epidemiology Collaboration (CKD-EPI) equation.

- Several renal biomarkers that may offer earlier detection of kidney disease, improve diagnosis of underlying histopathological findings and improve prognostication among HIV-infected persons with kidney disease are emerging, but require rigorous evaluation of their clinical utility.

- HIVAN is now an indication for HAART initiation even before a patient's CD4+ cell count falls below 350 cells/mm³. The efficacy of HAART for the treatment of non-HIVAN kidney disease remains unclear.

- A subset of HAART-treated HIV-infected individuals may experience ongoing kidney function decline as a result of HAART-related metabolic effects or adverse effects associated with long-term exposure to certain antiretroviral drugs (e.g., tenofovir, indinavir and atazanavir).

\section{Bibliography}

Papers of special note have been highlighted as:

- of interest

" of considerable interest

1 Franceschini N, Napravnik S, Eron JJ Jr, Szczech LA, Finn WF: Incidence and etiology of acute renal failure among ambulatory HIV-infected patients. Kidney Int. 67(4), 1526-1531 (2005).

2 Choi AI, Li Y, Parikh C, Volberding PA, Shlipak MG: Long-term clinical consequences of acute kidney injury in the HIV-infected. Kidney Int. 78(5), 478-485 (2010).

- Large observational study, composed primarily of men, that showed an association between acute kidney injury in HIV-infected individuals and several long-term outcomes.

3 Wyatt CM, Arons RR, Klotman PE, Klotman ME: Acute renal failure in hospitalized patients with HIV: risk factors and impact on in-hospital mortality. AIDS 20(4), 561-565 (2006).

4 Parkhie SM, Fine DM, Lucas GM, Atta MG: Characteristics of patients with HIV and biopsy-proven acute interstitial nephritis. Clin. J. Am. Soc. Nephrol. 5(5), 798-804 (2010).

5 Szczech LA, Grunfeld C, Scherzer R et al.: Microalbuminuria in HIV infection. AIDS 21(8), 1003-1009 (2007).
6 Fernando SK, Finkelstein FO, Moore BA, Weissman S: Prevalence of chronic kidney disease in an urban HIV infected population. Am. J. Med. Sci. 335(2), 89-94 (2008).

7 Jones CY, Jones CA, Wilson IB et al.: Cystatin $\mathrm{C}$ and creatinine in an HIV cohort: the Nutrition for Healthy Living Study. Am. J. Kidney Dis. 51(6), 914-924 (2008).

8 Szczech LA, Gupta SK, Habash R et al.: The clinical epidemiology and course of the spectrum of renal diseases associated with HIV infection. Kidney Int. 66(3), 1145-1152 (2004).

9 Yadav A, Vallabu S, Kumar D et al: HIVAN phenotype: consequence of epithelial mesenchymal transdifferentiation. Am. J. Physiol. Renal Physiol. 298(3), F734-F744 (2010).

10 Kumar D, Konkimalla S, Yadav A et al.: HIV-associated nephropathy: role of mammalian target of rapamycin pathway. Am. J. Pathol. 177(2), 813-821 (2010).

11 Kimmel PL, Phillips TM, Ferreira-Centeno A, Farkas-Szallasi T, Abraham AA, Garrett CT: HIV-associated immune-mediated renal disease. Kidney Int. 44(6), 1327-1340 (1993).

12 Estrella M, Fine DM, Gallant JE et al.: HIV type 1 RNA level as a clinical indicator of renal pathology in HIV-infected patients. Clin. Infect. Dis. 43(3), 377-380 (2006).
13 Szczech LA, Hoover DR, Feldman JG et al.: Association between renal disease and outcomes among HIV-infected women receiving or not receiving antiretroviral therapy. Clin. Infect. Dis. 39(8), 1199-1206 (2004).

14 Estrella MM, Parekh RS, Abraham A et al:: The impact of kidney function at highly active antiretroviral therapy initiation on mortality in HIV-infected women. J. Acquir. Immune Defic. Syndr. (2010) (In press).

15 Choi AI, Li Y, Deeks SG, Grunfeld C, Volberding PA, Shlipak MG: Association between kidney function and albuminuria with cardiovascular events in HIV-infected persons. Circulation 121(5), 651-658 (2010).

16 George E, Lucas GM, Nadkarni GN, Fine DM, Moore R, Atta MG: Kidney function and the risk of cardiovascular events in HIV-1-infected patients. AIDS 24(3), 387-394 (2010).

17 Hsu CY, Ordonez JD, Chertow GM, Fan D, McCulloch CE, Go AS: The risk of acute renal failure in patients with chronic kidney disease. Kidney Int. 74(1), 101-107 (2008).

18 Lucas GM, Lau B, Atta MG, Fine DM, Keruly J, Moore RD: Chronic kidney disease incidence, and progression to end-stage renal disease, in HIV-infected individuals: a tale of two races. J. Infect. Dis. 197(11), 1548-1557 (2008). 
19 Freedman BI, Soucie JM, Stone SM, Pegram S: Familial clustering of end-stage renal disease in blacks with HIV-associated nephropathy. Am. J. Kidney Dis. 34(2), 254-258 (1999).

20 Bruggeman LA, Dikman S, Meng C, Quaggin SE, Coffman TM, Klotman PE: Nephropathy in human immunodeficiency virus-1 transgenic mice is due to renal transgene expression. J. Clin. Invest. $100(1)$, 84-92 (1997).

21 Gharavi AG, Ahmad T, Wong RD et al.: Mapping a locus for susceptibility to HIV-1-associated nephropathy to mouse chromosome 3. Proc. Natl Acad. Sci. USA 101(8), 2488-2493 (2004).

22 Chan KT, Papeta N, Martino J et al.: Accelerated development of collapsing glomerulopathy in mice congenic for the HIVAN1 locus. Kidney Int. 75 (4), 366-372 (2009).

23 Papeta N, Chan KT, Prakash S et al.: Susceptibility loci for murine HIV-associated nephropathy encode trans-regulators of podocyte gene expression. J. Clin. Invest. 119 (5), 1178-1188 (2009).

= Using the transgenic mouse model for HIV-associated nephropathy (HIVAN), this study reports additional HIVAN susceptibility loci in mice and yields evidence of mechanisms underlying gene-environment interaction in HIVAN pathogenesis.

24 Quaggin SE: Genetic susceptibility to HIV-associated nephropathy. J. Clin. Invest. 119 (5), 1085-1089 (2009).

25 Imperatore G, Hanson RL, Pettitt DJ, Kobes S, Bennett PH, Knowler WC: Sib-pair linkage analysis for susceptibility genes for microvascular complications among Pima Indians with type 2 diabetes. Pima Diabetes Genes Group. Diabetes 47(5), 821-830 (1998).

26 DeWan AT, Arnett DK, Atwood LD et al.: A genome scan for renal function among hypertensives: the HyperGEN study. Am. J. Hum. Genet. 68(1), 136-144 (2001).

27 Kopp JB, Smith MW, Nelson GW et al.: $\mathrm{MYH} 9$ is a major-effect risk gene for focal segmental glomerulosclerosis. Nat. Genet. 40 (10), 1175-1184 (2008).

- - One of two original studies reporting the association of MYH9 variants and kidney disease among African-Americans. This study demonstrated a significant association between MYH9 E-1 risk haplotype and biopsy-proven HIVAN.

28 Kao WH, Klag MJ, Meoni LA et al.: MYH9 is associated with nondiabetic end-stage renal disease in African Americans. Nat. Genet. 40(10), 1185-1192 (2008).
- Demonstrated a strong association between certain MYH9 risk variants and nondiabetic end-stage kidney disease among African-Americans.

29 Arrondel C, Vodovar N, Knebelmann B et al.: Expression of the nonmuscle myosin heavy chain IIA in the human kidney and screening for MYH9 mutations in Epstein and Fechtner syndromes. J. Am. Soc. Nephrol. 13(1), 65-74 (2002).

30 Freedman BI, Hicks PJ, Bostrom MA et al.: Polymorphisms in the non-muscle myosin heavy chain 9 gene (MYH9) are strongly associated with end-stage renal disease historically attributed to hypertension in African Americans. Kidney Int. 75(7), 736-745 (2009).

31 Freedman BI, Kopp JB, Winkler CA et al.: Polymorphisms in the nonmuscle myosin heavy chain 9 gene (MYH9) are associated with albuminuria in hypertensive African Americans: the HyperGEN study. Am. J. Nephrol. 29(6), 626-632 (2009).

32 Freedman BI, Hicks PJ, Bostrom MA et al. Non-muscle myosin heavy chain 9 gene MYH9 associations in African Americans with clinically diagnosed type 2 diabetes mellitus-associated ESRD. Nephrol. Dial. Transplant. 24(11), 3366-3371 (2009).

33 Behar DM, Rosset S, Tzur S et al:: African ancestry allelic variation at the MYH9 gene contributes to increased susceptibility to non-diabetic end-stage kidney disease in Hispanic Americans. Hum. Mol. Genet. 19(9), 1816-1827 (2010).

34 Genovese G, Friedman DJ, Ross MD et al.: Association of trypanolytic ApoL1 variants with kidney disease in African Americans. Science 329(5993), 841-845 (2010).

-1. Demonstrated that APOL1 variants are strongly associated with kidney disease among African-Americans and may account for the excess risk previously attributed to MYH9. It also demonstrated that the same APOL1 variants are protective against Trypanosoma.

35 Tzur S, Rosset S, Shemer R et al.: Missense mutations in the APOL1 gene are highly associated with end stage kidney disease risk previously attributed to the MYH9 gene. Hum. Genet. 128(3), 345-350 (2010).

36 Freedman BI, Kopp JB, Langefeld CD et al.: The apolipoprotein L1 (APOL1) gene and nondiabetic nephropathy in African Americans. J. Am. Soc. Nephrol. (2010) (In press).

37 Winston JA, Klotman ME, Klotman PE: HIV-associated nephropathy is a late, not early, manifestation of HIV-1 infection. Kidney Int. 55(3), 1036-1040 (1999).
38 Levin ML, Palella F, Shah S, Lerma E, Butter J, Kanwar YS: HIV-associated nephropathy occurring before HIV antibody seroconversion. Am. J. Kidney Dis. 37(5), E39 (2001).

39 Bruggeman LA, Ross MD, Tanji N et al.: Renal epithelium is a previously unrecognized site of HIV-1 infection. J. Am. Soc. Nephrol. 11(11), 2079-2087 (2000).

40 Eitner F, Cui Y, Hudkins KL et al.: Chemokine receptor CCR5 and CXCR4 expression in HIV-associated kidney disease. J. Am. Soc. Nephrol. 11(5), 856-867 (2000).

41 Zhong J, Zuo Y, Ma J et al.: Expression of HIV-1 genes in podocytes alone can lead to the full spectrum of HIV-1-associated nephropathy. Kidney Int. 68(3), 1048-1060 (2005).

42 Zuo Y, Matsusaka T, Zhong J et al.: HIV-1 genes $v p r$ and $n e f$ synergistically damage podocytes, leading to glomerulosclerosis. J. Am. Soc. Nephrol. 17(10), 2832-2843 (2006).

43 Vallet-Pichard A, Pol S: Natural history and predictors of severity of chronic hepatitis $\mathrm{C}$ virus ( $\mathrm{HCV}$ ) and human immunodeficiency virus (HIV) co-infection. J. Hepatol. 44(1 Suppl.), S28-S34 (2006).

44 Wyatt CM, Malvestutto C, Coca SG, Klotman PE, Parikh CR: The impact of hepatitis $\mathrm{C}$ virus coinfection on HIV-related kidney disease: A systematic review and meta-analysis. AIDS 22(14), 1799-1807 (2008).

45 Mocroft A, Kirk O, Reiss P et al.: Estimated glomerular filtration rate, chronic kidney disease and antiretroviral drug use in HIV-positive patients. AIDS 24(11), 1667-1678 (2010).

- - This observational study in the EuroSIDA cohort demonstrates the long-term renal effects of several antiretroviral medications. This study demonstrated that long-term exposure to atazanavir was associated with kidney function decline.

46 Yanik EL, Lucas GM, Vlahov D, Kirk GD, Mehta SH: HIV and proteinuria in an injection drug user population. Clin. J. Am. Soc. Nephrol. (2010) (In press).

47 Fine DM, Garg N, Haas M et al.: Cocaine use and hypertensive renal changes in HIV-infected individuals. Clin. J. Am. Soc. Nephrol. 2(6), 1125-1130 (2007).

48 Stengel B, Couchoud C: Chronic kidney disease prevalence and treated end-stage renal disease incidence: a complex relationship. J. Am. Soc. Nephrol. 17(8), 2094-2096 (2006). 
49 Muntner P, Coresh J, Smith JC, Eckfeldt J, Klag MJ: Plasma lipids and risk of developing renal dysfunction: the atherosclerosis risk in communities study. Kidney Int. 58(1), 293-301 (2000).

50 Brown TT, Cole SR, Li X et al:: Antiretroviral therapy and the prevalence and incidence of diabetes mellitus in the multicenter AIDS cohort study. Arch. Intern. Med. 165(10), 1179-1184 (2005).

51 Seaberg EC, Munoz A, Lu M et al: Association between highly active antiretroviral therapy and hypertension in a large cohort of men followed from 1984 to 2003. AIDS 19(9), 953-960 (2005).

52 Onen NF, Overton ET, Seyfried W et al.: Aging and HIV infection: a comparison between older HIV-infected persons and the general population. HIV Clin. Trials 11(2), 100-109 (2010).

53 Riddler SA, Smit E, Cole SR et al.: Impact of HIV infection and HAART on serum lipids in men. JAMA 289 (22), 2978-2982 (2003).

54 Choi AI, Shlipak MG, Hunt PW, Martin JN, Deeks SG: HIV-infected persons continue to lose kidney function despite successful antiretroviral therapy. AIDS 23(16), 2143-2149 (2009).

55 Nguyen MT, Maynard SE, Kimmel PL: Misapplications of commonly used kidney equations: renal physiology in practice. Clin. J. Am. Soc. Nephrol. 4(3), 528-534 (2009).

56 Mehta RL, Kellum JA, Shah SV et al.: Acute kidney injury network: report of an initiative to improve outcomes in acute kidney injury. Crit. Care 11(2), R31 (2007).

57 Gupta SK, Eustace JA, Winston JA et al.: Guidelines for the management of chronic kidney disease in HIV-infected patients: recommendations of the HIV Medicine Association of the Infectious Diseases Society of America. Clin. Infect. Dis. 40(11), 1559-1585 (2005).

58 Siedner MJ, Atta MG, Lucas GM, Perazella MA, Fine DM: Poor validity of urine dipstick as a screening tool for proteinuria in HIV-positive patients. J. Acquir. Immune Defic. Syndr. 47(2), 261-263 (2008).

59 Levey AS, Coresh J, Balk E et al:: National kidney foundation practice guidelines for chronic kidney disease: evaluation, classification, and stratification. Ann. Intern. Med. 139(2), 137-147 (2003).

60 Ginsberg JM, Chang BS, Matarese RA, Garella S: Use of single voided urine samples to estimate quantitative proteinuria. N. Engl. J. Med. 309(25), 1543-1546 (1983).
61 Price CP, Newall RG, Boyd JC: Use of protein:creatinine ratio measurements on random urine samples for prediction of significant proteinuria: a systematic review. Clin. Chem. 51(9), 1577-1586 (2005).

62 Cockcroft DW, Gault MH: Prediction of creatinine clearance from serum creatinine. Nephron 16(1), 31-41 (1976).

63 Levey AS, Bosch JP, Lewis JB et al.: A more accurate method to estimate glomerular filtration rate from serum creatinine: a new prediction equation. Ann. Intern. Med. 130, 461-470 (1999).

64 Levey AS, Greene T, Kusek JW et al.: A simplified equation to predict glomerular filtration rate from serum creatinine. J. Am. Soc. Nephrol. 11, 115A (2000).

65 Levey AS, Coresh J, Greene T et al.: Using standardized serum creatinine values in the modification of diet in renal disease study equation for estimating glomerular filtration rate. Ann. Intern. Med. 145(4), 247-254 (2006).

66 Levey AS, Stevens LA, Schmid CH et al.: A new equation to estimate glomerular filtration rate. Ann. Intern. Med. 150(9), 604-612 (2009).

"I This study by the Chronic Kidney DiseaseEpidemiology Collaboration generated a new more accurate and precise equation for estimating kidney function in the general population: the CKD-EPI equation.

67 Rule AD, Larson TS, Bergstralh EJ, Slezak JM, Jacobsen SJ, Cosio FG: Using serum creatinine to estimate glomerular filtration rate: accuracy in good health and in chronic kidney disease. Ann. Intern. Med. 141(12), 929-937 (2004).

68 Bostom AG, Kronenberg F, Ritz E: Predictive performance of renal function equations for patients with chronic kidney disease and normal serum creatinine levels. J. Am. Soc. Nephrol. 13(8), 2140-2144 (2002).

69 Huang E, Hewitt RG, Shelton M, Morse GD: Comparison of measured and estimated creatinine clearance in patients with advanced HIV disease. Pharmacotherapy 16(2), 222-229 (1996).

70 Noormohamed SE, Katseres JK, Stapleton JT: Poor correlation between published methods to predict creatinine clearance and measured creatinine clearance in asymptomatic HIV infected individuals. Ren. Fail. 20(4), 627-633 (1998).

71 Smith BL, Sarnoski TP, Dennis S, Luke DR: Failure of predicted creatinine clearance equations in HIV-seropositive patients. Int. J. Clin. Pharmacol. Ther. Toxicol. 30(10), 394-399 (1992).
72 Barraclough K, Er L, Ng F, Harris M, Montaner J, Levin A: A comparison of the predictive performance of different methods of kidney function estimation in a wellcharacterized HIV-infected population. Nephron Clin. Pract. 111(1), c39-c48 (2009).

73 Shlipak MG, Wassel Fyr CL, Chertow GM et al:: Cystatin $\mathrm{C}$ and mortality risk in the elderly: the health, aging, and body composition study. J. Am. Soc. Nephrol. 17(1), 254-261 (2006).

74 Kottgen A, Selvin E, Stevens LA, Levey AS, Van Lente F, Coresh J: Serum cystatin C in the united states: The Third National Health and Nutrition Examination Survey (NHANES III). Am. J. Kidney Dis. 51(3), 385-394 (2008).

75 Stevens LA, Coresh J, Schmid CH et al.: Estimating GFR using serum cystatin $\mathrm{C}$ alone and in combination with serum creatinine: a pooled analysis of 3,418 individuals with CKD. Am. J. Kidney Dis. 51(3), 395-406 (2008).

76 Stevens LA, Schmid CH, Greene T et al.: Factors other than glomerular filtration rate affect serum cystatin C levels. Kidney Int. 75(6), 652-660 (2009).

- This observational study includes detailed analyses showing several extra-renal factors which influence serum cystatin $\mathrm{C}$ levels in HIV-uninfected persons.

77 Odden MC, Scherzer R, Bacchetti P et al: Cystatin $\mathrm{C}$ level as a marker of kidney function in human immunodeficiency virus infection: the FRAM study. Arch. Intern. Med. 167(20), 2213-2219 (2007).

78 Mauss S, Berger F, Kuschak D et al.: Cystatin C as a marker of renal function is affected by HIV replication leading to an underestimation of kidney function in HIV patients. Antivir. Ther. 13(8), 1091-1095 (2008).

79 Mocroft A, Wyatt C, Szczech L et al.: Interruption of antiretroviral therapy is associated with increased plasma cystatin C. AIDS 23(1), 71-82 (2009).

80 Bernard AM, Moreau D, Lauwerys R: Comparison of retinol-binding protein and $\beta 2$-microglobulin determination in urine for the early detection of tubular proteinuria. Clin. Chim. Acta 126(1), 1-7 (1982).

81 Norden AG, Scheinman SJ, Deschodt-Lanckman MM et al:: Tubular proteinuria defined by a study of dent's (CLCN5 mutation) and other tubular diseases. Kidney Int. 57(1), 240-249 (2000).

82 Price RG: The role of NAG (N-acetyl- $\beta$-Dglucosaminidase) in the diagnosis of kidney disease including the monitoring of nephrotoxicity. Clin. Nephrol. 38(Suppl. 1), S14-S19 (1992). 
83 Kuwabara T, Mori K, Mukoyama M et al.: Urinary neutrophil gelatinase-associated lipocalin levels reflect damage to glomeruli, proximal tubules, and distal nephrons. Kidney Int. 75(3), 285-294 (2009).

84 Hall AM, Edwards SG, Lapsley M et al: Subclinical tubular injury in HIV-infected individuals on antiretroviral therapy: a cross-sectional analysis. Am. J. Kidney Dis. 54(6), 1034-1042 (2009).

85 Landro L, Damas JK, Flo TH et al.: Decreased serum lipocalin-2 levels in human immunodeficiency virus-infected patients: Increase during highly active anti-retroviral therapy. Clin. Exp. Immunol. 152(1), 57-63 (2008).

86 Soler-Garcia AA, Johnson D, Hathout Y, Ray PE: Iron-related proteins: candidate urine biomarkers in childhood HIV-associated renal diseases. Clin. J. Am. Soc. Nephrol. 4(4), 763-771 (2009).

87 Paragas N, Nickolas TL, Wyatt C et al: Urinary NGAL marks cystic disease in HIV-associated nephropathy. J. Am. Soc. Nephrol. 20(8), 1687-1692 (2009).

88 Tabatabai S, Sperati CJ, Atta MG et al.: Predictors of complication after percutaneous ultrasound-guided kidney biopsy in HIV-infected individuals: possible role of hepatitis $\mathrm{C}$ and HIV co-infection. Clin. J. Am. Soc. Nephrol. 4(11), 1766-1773 (2009).

89 Choi AI, Rodriguez RA, Bacchetti P et al.: Low rates of antiretroviral therapy among HIV-infected patients with chronic kidney disease. Clin. Infect. Dis. 45(12), 1633-1639 (2007).

90 Lucas GM, Eustace JA, Sozio S, Mentari EK, Appiah KA, Moore RD: Highly active antiretroviral therapy and the incidence of HIV-1-associated nephropathy: a 12-year cohort study. AIDS 18(3), 541-546 (2004).

91 Yahaya I, Uthman AO, Uthman MM: Interventions for HIV-associated nephropathy. Cochrane Database Syst. Rev. 4, CD007183 (2009).

92 Hammer SM, Eron JJ Jr, Reiss P et al.: Antiretroviral treatment of adult HIV infection: 2008 recommendations of the International AIDS Society-USA panel. JAMA 300 (5), 555-570 (2008).

93 Eustace JA, Nuermberger E, Choi M, Scheel PJ Jr, Moore R, Briggs WA: Cohort study of the treatment of severe HIV-associated nephropathy with corticosteroids. Kidney Int. 58(3), 1253-1260 (2000).

94 Cihlar T, Ho ES, Lin DC, Mulato AS: Human renal organic anion transporter 1 (hOAT1) and its role in the nephrotoxicity of antiviral nucleotide analogs. Nucleosides Nucleotides Nucleic Acids 20(4-7), 641-648 (2001).

95 Ray AS, Cihlar T, Robinson KL et al.: Mechanism of active renal tubular efflux of tenofovir. Antimicrob. Agents Chemother. 50(10), 3297-3304 (2006).

96 Kohler JJ, Hosseini SH, Hoying-Brandt A et al.: Tenofovir renal toxicity targets mitochondria of renal proximal tubules. Lab. Invest. 89(5), 513-519 (2009).

97 Peyriere H, Reynes J, Rouanet I et al.: Renal tubular dysfunction associated with tenofovir therapy: report of 7 cases. J. Acquir. Immune Defic. Syndr. 35(3), 269-273 (2004).

98 Mathew G, Knaus SJ: Acquired Fanconi's syndrome associated with tenofovir therapy. J. Gen. Intern. Med. 21(11), C3-C5 (2006).

99 Earle KE, Seneviratne T, Shaker J, Shoback D: Fanconi's syndrome in $\mathrm{HIV}^{+}$ adults: report of three cases and literature review. J. Bone Miner. Res. 19(5), 714-721 (2004).

100 Di Biagio A, Rosso R, Monteforte P, Russo R, Rovetta G, Viscoli C: Whole body bone scintigraphy in tenofovir-related osteomalacia: a case report. J. Med. Case Reports 3, 8136 (2009).

101 Perrot S, Aslangul E, Szwebel T, Caillat-Vigneron N, Le Jeunne C: Bone pain due to fractures revealing osteomalacia related to tenofovir-induced proximal renal tubular dysfunction in a human immunodeficiency virus-infected patient. J. Clin. Rheumatol. 15(2), 72-74 (2009).

102 Rollot F, Nazal EM, Chauvelot-Moachon L et al.: Tenofovir-related Fanconi syndrome with nephrogenic diabetes insipidus in a patient with acquired immunodeficiency syndrome: the role of lopinavir-ritonavirdidanosine. Clin. Infect. Dis. 37(12), e174-e176 (2003).

103 Coca S, Perazella MA: Rapid communication: acute renal failure associated with tenofovir: evidence of drug-induced nephrotoxicity. Am. J. Med. Sci. 324(6), 342-344 (2002).

104 Gallant JE, Staszewski S, Pozniak AL et al.: Efficacy and safety of tenofovir DF vs stavudine in combination therapy in antiretroviral-naive patients: a 3-year randomized trial. JAMA 292(2), 191-201 (2004).

105 Izzedine H, Hulot JS, Vittecoq D et al.: Long-term renal safety of tenofovir disoproxil fumarate in antiretroviral-naive HIV-1infected patients. data from a double-blind randomized active-controlled multicentre study. Nephrol. Dial. Transplant. 20(4), 743-746 (2005).
106 Arribas JR, Pozniak AL, Gallant JE et al: Tenofovir disoproxil fumarate, emtricitabine, and efavirenz compared with zidovudine/ lamivudine and efavirenz in treatment-naive patients: 144-week analysis. J. Acquir. Immune Defic. Syndr. 47(1), 74-78 (2008).

107 Jones R, Stebbing J, Nelson M et al.: Renal dysfunction with tenofovir disoproxil fumarate-containing highly active antiretroviral therapy regimens is not observed more frequently: a cohort and case-control study. J. Acquir. Immune Defic. Syndr. 37(4), 1489-1495 (2004).

108 Gallant JE, Parish MA, Keruly JC, Moore RD: Changes in renal function associated with tenofovir disoproxil fumarate treatment, compared with nucleoside reverse-transcriptase inhibitor treatment. Clin. Infect. Dis. 40(8), 1194-1198 (2005).

109 Gallant JE, Moore RD: Renal function with use of a tenofovir-containing initial antiretroviral regimen. AIDS 23(15), 1971-1975 (2009).

110 Rodriguez-Novoa S, Labarga P, Soriano V et al:: Predictors of kidney tubular dysfunction in HIV-infected patients treated with tenofovir: a pharmacogenetic study. Clin. Infect. Dis. 48(11), e108-e116 (2009).

111 Young B, Buchacz K, Moorman A, Wood KC, Brooks JT; HIV Outpatient Study (HOPS) Investigators: Renal function in patients with preexisting renal disease receiving tenofovir-containing highly active antiretroviral therapy in the HIV outpatient study. AIDS Patient Care STDS 23(8), 589-592 (2009).

112 Marroni M, Gaburri M, Mecozzi F, Baldelli F: Acute interstitial nephritis secondary to the administration of indinavir. Ann. Pharmacother. 32(7-8), 843-844 (1998).

113 Brodie SB, Keller MJ, Ewenstein BM, Sax PE: Variation in incidence of indinavir-associated nephrolithiasis among HIV-positive patients. AIDS 12(18), 2433-2437 (1998).

114 Chan-Tack KM, Truffa MM, Struble KA, Birnkrant DB: Atazanavir-associated nephrolithiasis: cases from the US Food and Drug Administration's adverse event reporting system. AIDS 21(9), 1215-1218 (2007).

115 Izzedine $H$, M'rad MB, Bardier A, Daudon M, Salmon D: Atazanavir crystal nephropathy. AIDS 21(17), 2357-2358 (2007). 


\section{MedscapeCME“ Recent developments in HIV-related kidney disease}

To obtain credit, you should first read the journal article. After reading the article, you should be able to answer the following, related, multiple-choice questions. To complete the questions and earn continuing medical education (CME) credit, please go to www.medscapecme.com/journal/hivtherapy. Credit cannot be obtained for tests completed on paper, although you may use the worksheet below to keep a record of your answers. You must be a registered user on Medscape.com. If you are not registered on Medscape.com, please click on the New Users: Free Registration link on the left hand side of the website to register. Only one answer is correct for each question. Once you successfully answer all post-test questions you will be able to view and/or print your certificate. For questions regarding the content of this activity, contact the accredited provider,
CME@medscape.net. For technical assistance, contact CME@webmd.net. American Medical Association's Physician's Recognition Award (AMA PRA) credits are accepted in the US as evidence of participation in CME activities. For further information on this award, please refer to http://www.ama-assn.org/ama/pub/ category/2922.html. The AMA has determined that physicians not licensed in the US who participate in this CME activity are eligible for AMA PRA Category 1 Credits ${ }^{\mathrm{TM}}$. Through agreements that the AMA has made with agencies in some countries, AMA PRA credit is acceptable as evidence of participation in CME activities. If you are not licensed in the US and want to obtain an AMA PRA CME credit, please complete the questions online, print the certificate and present it to your national medical association.

\section{Activity evaluation: where 1 is strongly disagree and 5 is strongly agree.}

$\begin{array}{llllll} & \mathbf{5} & \mathbf{3} & \mathbf{4} & \mathbf{5} & \mathbf{3} \\ \text { The activity supported the learning objectives. } & & \\ \text { The material was organized clearly for learning to occur. } \\ \text { The content learned from this activity will impact my practice. } \\ \text { The activity was presented objectively and free of commercial bias. }\end{array}$

1. A 39-year-old, black man presents with a 15-year history of HIV infection and chronic kidney disease (CKD). He has been off all medications for several years and was just admitted to the hospital with symptomatic kidney disease.

Which of the following statements about risk factors for kidney disease in this patient is most accurate?
A Blacks are at a lower risk for HIV-related kidney disease
B The presence of hepatitis $C$ coinfection paradoxically reduces the risk for kidney disease
C Variants of the MYH9 gene may promote HIVAN
D Variants of the APOL1 gene oppose kidney disease promoted by other genetic factors

2. You and the patient discuss his history of kidney disease. Which of the following statements about the diagnosis of kidney disease among patients with HIV infection is most accurate?
A A dipstick urinalysis is sufficient for screening at the time of HIV diagnosis
B The Chronic Kidney Disease Epidemiology Collaboration (CKD-EPI) equation is probably the most accurate calculation in determining estimated glomerular filtration rate (eGFR)
C eGFR is the most important element in the diagnosis of acute kidney injury
D $\mathrm{N}$-acetyl-beta-D-glucosaminidase is now considered the gold standard to diagnose CKD among patients with HIV infection 
3. The patient is diagnosed with HIV-associated nephropathy (HIVAN). Which of the following treatments is most effective for HIVAN?

$\square$ A Immediate initiation of highly active antiretroviral therapy (HAART)

B Initiation of HAART when the eGFR improves to $60 \mathrm{ml} / \mathrm{min} / 1.73 \mathrm{~m}^{2}$

C Renin-angiotensin inhibitors

D Corticosteroids

4. Which of the following should you consider in regard to the effect of HAART on CKD?

$\square$ A Tenofovir promotes renal damage by reducing afferent blood flow to the nephron

B Tenofovir may promote Fanconi syndrome

C Tenofovir consistently reduces eGFR over time

D Renal complications do not occur with the current dosing of indinavir 